\title{
Magnetic resonance imaging in cardiac syndrome $X$
}

\author{
Syed Maqbool Ahmad, D.M., Hilal Rather, D.M., Khurshid lqbal, D.M., Nisar A. Tramboo D.M., Vicar M. Jan, \\ D.M., Khursheed Aslam D.M. \\ Department of Cardiology, Sher-i-Kashmir Institute of Medical Sciences, Srinagar
}

\section{A B S T R A C T}

BACKGROUND: Cardiac syndrome $X$ is a subject with yet unsettled etiology and management. Conventional investigations have not been able to establish that chest pain is due to myocardial ischemia. Magnetic resonance imaging has higher resolution and is more accurate for detecting ischemia.

AIMS AND OBJECTIVES: To establish subendocardial ischemia as the cause of chest pain in cardiac syndrome $X$ by virtue of stress perfusion cardiac MRI.

METHODS: Contrast enhanced cardiac MRI was performed in 15 cases and 7 matched controls both at rest and during a six minute infusion of adenosine. Both visual and quantitive analysis were performed. In quantitative analysis both myocardial perfusion index and myocardial perfusion reserve index was measured.

RESULTS: There was a significant increase in myocardial perfusion in both subendocardium as well as in subepicardium in both cases as well as in controls upon stress with adenosine. In controls the subendocardial perfusion index rose from $0.13 \pm 0.3$ to $0.18 \pm .03$ and in the subepicardium from $0.12 \pm .02$ to $0.18 \pm .03$. In patients with cardiac syndrome $X$ subendocardial perfusion index rose from $0.14 \pm .03$ to $0.19 \pm .03$ and subepicardial perfusion index rose from $0.13+.03$ to $0.19 \pm .03$. Visual analysis showed short lasting subendocardial dark rim artificats in both cases and controls which lasted for only 3 to 5 beats.

CONCLUSION: Our cardiovascular MR study of patients with cardiac syndrome $X$ demonstrated significant and almost similar magnitude adenosine induced increase in both subendocardial and subepicardial myocardial perfusion indices in both study as well as control group. We found no evidence of subendocardial ischemia in patients with cardiac syndrome X. JMS $2011 ; 14(2): 46-51$

Key Word: Cardic syndromeX, MRI, ischemia, subendocardium

\section{Introduction}

Angiography became widely applicable in 60's, and soon it was realized that about $20 \%$ of patients with anginal chest pain have normal coronary angiograms ${ }^{1}$. KEMP in 1973 coined the term cardiac syndrome X for such patients ${ }^{2}$. Some physicians regard this as sufficient to diagnose CSX, the so-called broad diagnosis of $\mathrm{CSX}^{3}$, however the classical definition of

Correspondence and Reprint request to:

Dr. Syed Maqbool Ahmad

Department of Cardiology

SKIMS, Soura, Srinagar, J\&K - 190011

Email: syedmaqbool20@yahoo.com cardiac syndrome X (CSX) stands as angina like pain on effort, ST segment depression on exercise stress test and normal coronary arteries at angiography in the absence of any other cardiac or systemic diseases (for example, hypertension or diabetes) known to influence vascular function ${ }^{4}$. Many studies have taken abnormal myocardial SPECT in place of exercise stress test, and have defined syndrome $\mathrm{x}$ as chest pain, normal coronaries, abnormal exercise ECG and/or reversible defects on myocardial SPECT ${ }^{5,6}$. The pathophysiology of cardiac syndrome $\mathrm{x}$ has mainly centered around microvascular dysfunction, although abnormal pain perception has also been proposed by many studies. Numerous non invasive imaging studies have been carried out to determine whether ischemia is 
present. In the majority of patients, ventricular function under conditions of rest or stress - as assessed by radionuclide ventriculography $^{7}$ or echocardiography ${ }^{8}$ has been normal. Thallium201 myocardial-perfusion studies of patients with syndrome X have found abnormal results in a proportion of patients ranging from a few to the majority ${ }^{9}$. Some studies in which positronemission tomography (PET) was used have shown abnormal heterogeneity in perfusion ${ }^{10}$, whereas others have shown no abnormalities $^{12}$. A global assessment of published data shows that metabolic evidence of stress induced myocardial ischaemia, including myocardial lactate production, coronary sinus oxygen desaturation and coronary sinus $\mathrm{pH}$ reduction, has clearly been obtained in at least a subgroup ( $\geq 20 \%)$ of patients with CSX ${ }^{4}$ Notably, in a recent study Buchthal et al by assessing myocardial phosphorus 31 metabolism by MR spectroscopy, showed typical metabolic ischaemic changes during a handgrip test in about $20 \%$ of women with $\mathrm{CSX}^{11}$. More recent studies however, with stricter criteria for the selection of patients suggest that lactate production is normal in patients with syndrome $\mathrm{X}^{12}$ Cardiac MRI recently has been found to be accurate enough for detection of coronary ischemia. Panting et al in a cardiac MR study in 2002 demon- presented with classical cardiac syndrome $\mathrm{x}$. Fifteen cases and seven controls gave written informed consent out of screened fifty cases and ten controls. The study was completed in a period of two years w.e.f., Jan 2009 to Dec 2010. Inclusion criteria for cases were typical effort angina, positive exercise stress test $(0.1 \mathrm{mV}$ horizontal or downsloping ST-segment depression of $80 \mathrm{msec}$ after the J point) and normal coronary angiogram, interpreted by two different observers. HTN, diabetes, dyslipidemia, LVH, valvular heart disease, cardiomyopathy, smoking were ruled out. Controls were healthy subjects with no history of chest pain. This study was approved by institutional ethical committee report. Echocardiography was done to rule out cardiomyopathy, LVH, valvular heart disease. Tread mill test required (bruce protocol was followed)-down sloping or horizontal ST segment depression of $1 \mathrm{~mm}$ or more for $80 \mathrm{msec}$ after J point. Coronary angiography - all routine views with additional (if necessary) were taken. Intracoronary ergonovine was used to rule out coronary spasm. Coronary angiogram was seen by two different observers to rule out epicardial coronary artery disease. Demographic characteristics of the cases and controls were almost similar (Table 1).

Table 1. Demographic characteristics of the saese and controls

\begin{tabular}{|c|c|c|c|c|c|c|c|c|c|}
\hline & \multicolumn{8}{|c|}{ Demographic Characteristics } & \multirow{3}{*}{ pvalue } \\
\hline & \multicolumn{4}{|c|}{ Study } & \multicolumn{4}{|c|}{ Control } & \\
\hline & $\overline{\min }$ & Max & Mean & SD & $\min$ & $\max$ & Mean & SD & \\
\hline Age (yr) & 47 & 66 & 56.8 & 4.9 & 50 & 56 & 54.1 & 2.0 & 0.117 \\
\hline Blood Sugar (F) & 68 & 98 & 84.3 & 7.4 & 79 & 90 & 87.0 & 3.9 & 0.303 \\
\hline Blood Sugar (PP) & 112 & 136 & 126.8 & 7.7 & 112 & 134 & 125.0 & 8.0 & 0.571 \\
\hline Total Cholestrol & 132 & 200 & 160.4 & 20.1 & 100 & 154 & 138.0 & 18.1 & 0.018 \\
\hline Triglycerides & 128 & 172 & 146.7 & 14.8 & 110 & 150 & 135.1 & 14.8 & 0.230 \\
\hline LDL & 67 & 90 & 79.1 & 7.1 & 68 & 89 & 78.1 & 6.3 & 0.697 \\
\hline HDL & 40 & 60 & 50.7 & 5.0 & 46 & 55 & 50.7 & 3.5 & 0.915 \\
\hline Systolic Blood Pressure & 110 & 134 & 122.4 & 6.8 & 110 & 120 & 115.4 & 5.1 & 0.018 \\
\hline Diastolic Blood Pressure & 70 & 86 & 78.5 & 5.6 & 70 & 80 & 73.1 & 4.1 & 0.039 \\
\hline
\end{tabular}

strated subendocardial ischemia in patients with cardiac syndrome $\mathrm{X}^{13}$, another in 2007 found results contrary to the same $^{14}$, but there were valid differences between the two on the basis of which the first study could not be negated. Patients with cardiac syndrome $\mathrm{x}$ roam around from physician to physician, may undergo multiple angiograms and change in treatment from time to time. We have undertaken this study to consolidate subendocardial ischemia as the cause for chest pain in cardiac syndrome X.

\section{Material and Methods}

This study was a prospective study conducted in collaboration by departments of Cardiology and Radiodiagnosis, Sher-i-Kashmir Institute of Medical Sciences, Soura, Srinagar, Jammu and Kashmir on patients who

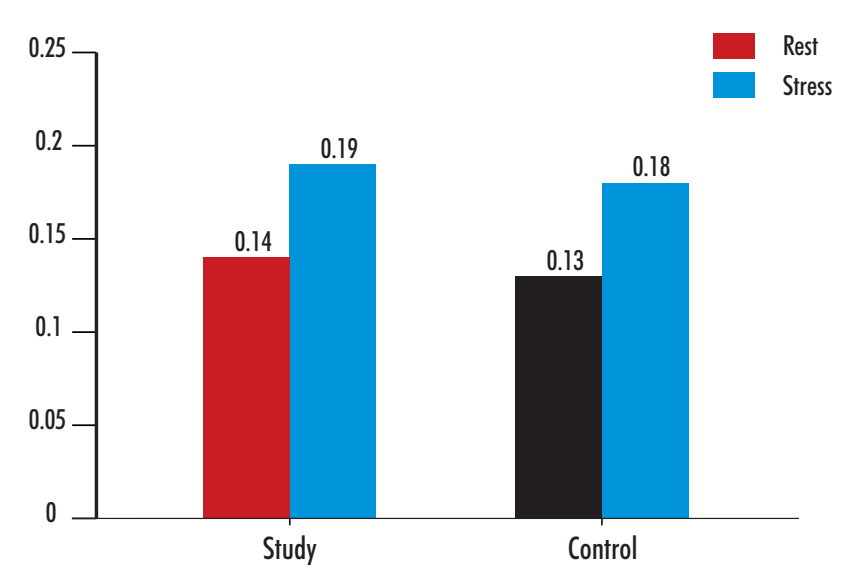

FIGURE 1. Subendocardial Perfusion Index 


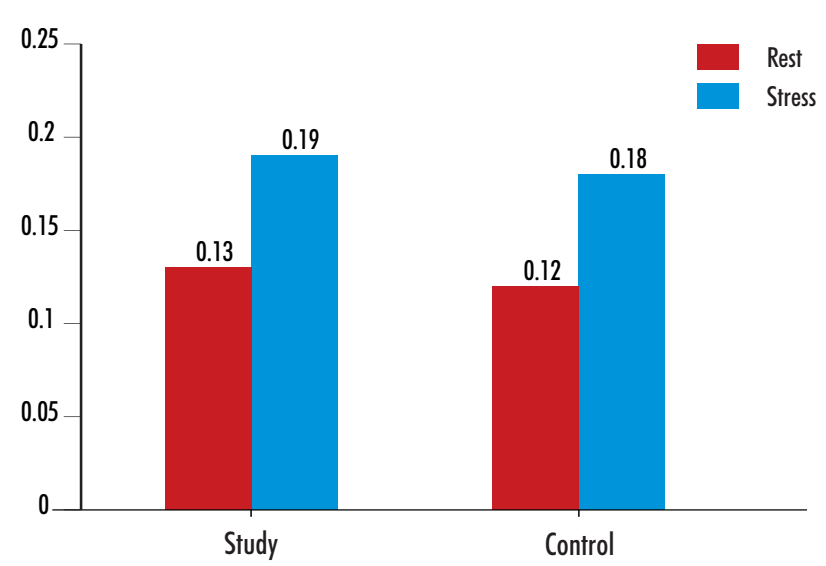

FIGURE 2: Subepicardial Perfusion Index

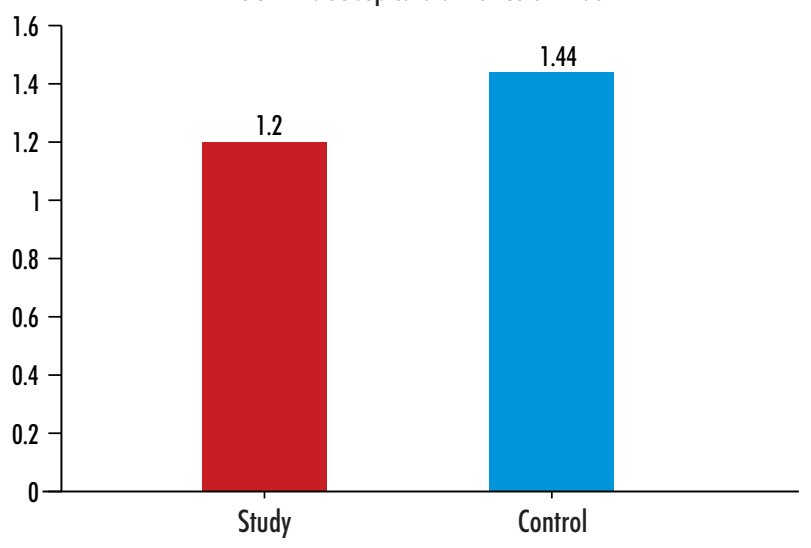

FIGURE 3: Subendocardial Reserve Index

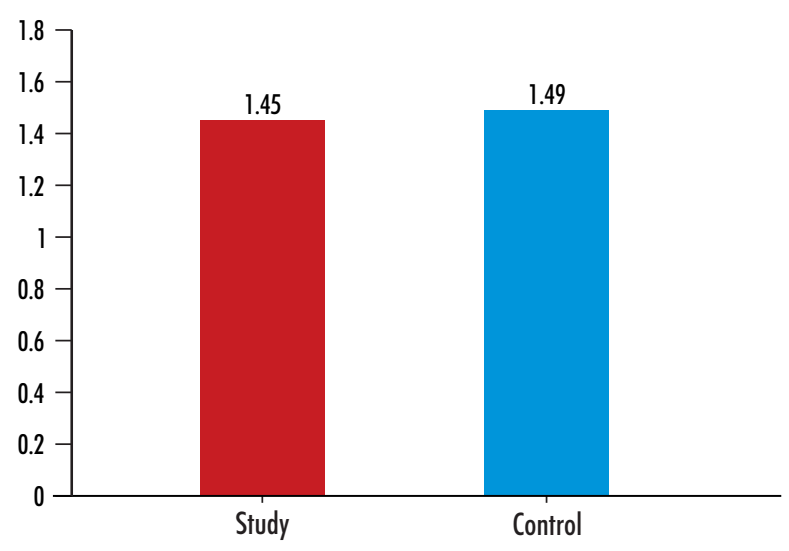

FIGURE 4: Subepicardial Perfusion Reserve Index

\section{Cardiac MRI}

Cardiovascular magnetic resonance imaging was performed with use of a 1.5-T scanner (SIEMENS, SINGO) that used a gradient-echo sequence with a 90-degree saturation pulse for T1 weighting. A cardiac phase-array receiver coil was used with sequence variables as follows: time to echo- $1.2 \mathrm{msec}$; repetition time-3 msec; phase matrix-64; slice thickness-10 $\mathrm{mm}$; Field of view- 450 by $225 \mathrm{~mm}$ yielding a pixel size of 3.5 by $3.5 \mathrm{~mm}$ interpolated to 1.75 by $1.75 \mathrm{~mm}$. The two-slice sequence was started on the $\mathrm{R}$ wave for systolic gating and to ensure an adequate acquisition window during any adenosineinduced tachycardia. Studies were performed at rest and during a six-minute infusion of adenosine (140 $\mu \mathrm{g}$ per kilogram of body weight per minute) to achieve intense coronary hyperemia. The two studies were separated by 20 minutes to allow equilibration of the contrast agent after the first injection. Two short-axis left ventricular slices were placed one third and two thirds of the distance from base to apex, with acquisition every cardiac cycle for 50 beats. A bolus of gadopentetate dimeglumine ( $0.05 \mathrm{mmol}$ per kilogram) was injected at a rate of $5 \mathrm{ml}$ per second for each first-pass study by means of a power injector. The images were analyzed quantitatively, in a masked fashion, and were presented in random order. Each series of images was analyzed by measuring the signal in regions of interest in the left ventricular blood pool and myocardium. For analysis, the myocardium was divided into subendocardial and sub-epicardial regions, which were drawn with the outer borders close to the endocardial and epicardial surfaces and with the inner borders adjacent to each other in the mid-wall. The analysis was performed with software designed in house . The regions of interest were drawn on a single image and propagated automatically throughout the perfusion series. Each image was then checked for positioning, and adjustments were made for any respiratory movement. The intervals between images were calculated from the electrocardiographic trace obtained during acquisition, and from these measurements, curves showing signal intensity plotted against time were constructed for each region of interest. An index of myocardial perfusion was then calculated with the use of myocardial slope measurements. Curve fitting was used to obtain the slope of the first-pass contrast enhancement for each of the myocardial regions of interest and the left ventricular blood-pool region of interest. The myocardial slope was then normalized by dividing it by the left ventricular blood-pool slope. This method compensates for changes in the input function caused by the effects of adenosine on heart rate and systemic circulation. The ratio of the myocardial perfusion index during stress to that with the subject at rest was defined as the myocardial-perfusion reserve index. Subepicardial perfusion and subendocardial perfusion were compared to determine the degree of heterogeneity across the myocardial wall. Transmural perfusion was assessed by combining the subepicardial and subendocardial regions of interest. Heterogeneity within the subendocardial regions of interest was assessed by visual scoring of 6 segments in each slice (total for the two slices, 12 segments).

In addition to undergoing magnetic resonance imaging, all subjects graded the level of pain associated with the adenosine infusion on the following scale. 1) no pain; 2)mild discomfort; 3)moderate but bearable pain; 4)severe pain; 5)the worst pain ever experienced.

\section{Statistical Analysis}

Data was described as mean \pm SD and percentage. The inter and intra group comparisons were made by Mann 
Whitney $\mathrm{U}$ test and wilcoxan signed rank test. $p$ value of $<0.05$ was considered significant. The soft ware used was SPSS 11.5 and MS Excel.

\section{Results}

There was a significant increase in myocardial perfusion in both subendocardiun as well as in subepicardium in both cases as well as in controls upon stress with adenosine.

In controls the subendocardial perfusion index rose from $0.13 \pm .03$ to $0.18 \pm .03$ and in the subepicardium from $0.12 \pm .02$ to $0.18 \pm .03$. In patients with cardiac syndrome $\mathrm{x}$ subendocardial perfusion index rose from $0.14 \pm .03$ to $0.19 \pm .03$ and subepicardial perfusion index rose from $0.13 \pm .03$ to $0.19 \pm .03$.

Subendocardial perfusion reserve index and subepicardial perfusion reserve index were $1.35 \pm 0.25$ and $1.45 \pm 0.13$ respectively in cases and $1.44 \pm .040$ and $1.49 \pm 0.27$ respectively in controls.

Subendocardial/subepicardial perfusion reserve index was $0.94 \pm 0.20$ in cases and $1.01 \pm 0.37$ in controls .

Transmural perfusion reserve index was $1.39 \pm 0.12$ in cases and $1.44 \pm 0.23$ in controls.

Visual analysis showed short lasting subendocardial dark rim artifacts in both cases and controls which lasted for only 3 to 5 beats.

Chest pain in response to adenosine was seen in both cases as well as controls.

\section{Visual analysis}

Upon visual analysis we found that most of the patients as well as controls showed initial subendocardial signal reduc- tions on the first-pass cardiovascular MR images, which disappeared after approximately three to five heartbeats.

\section{Discussion}

Both the cases and controls in our study showed a significant perfusion response of almost similar magnitude in response to adenosine in both the subendocardium and subepicardium. We therefore found no evidence of subendocardial ischemia in our patients with cardiac syndromeX.

Subendocardial perfusion index in our study increased from rest to stress in patients with syndrome $\mathrm{x}$ from $0.14 \pm .03$ to $0.19 \pm .03 \&$ in controls from $0.13 \pm 0.03$ to $0.18 \pm 0.03$. This is in contrast to a previous study ${ }^{13}$ where subendocardial perfusion in patients with syndrome $\mathrm{X}$ did not increase significantly in comparison to controls, and in accord with a previous study ${ }^{14}$ where subendocardial perfusion increased significantly in response to stress with adenosine in patients with syndrome $\mathrm{X}$. Both our study and the study by panting etal and the study by Vermeltfoort et al showed a significant and a similar magnitude of increase in subepicardial perfusion.

Characteristics of our patient group were almost similar to the control group with an insignificant $p$ value in all characteristics. These characteristics were also almost similar to the study group and the control group who participated in the study by Panting et al. We used the same definition of cardiac syndromre $\mathrm{X}$ as that in the study by Panting et al . This definition has been used by almost 42 studies out of 57 studies so far published pubmed from 2003 to $2008^{15}$. Vermeltfoort et $a^{14}$ in their study used the definition of cardiac syndrome as exrtional angina; an abnormal exercise electrocardiogram suggesting
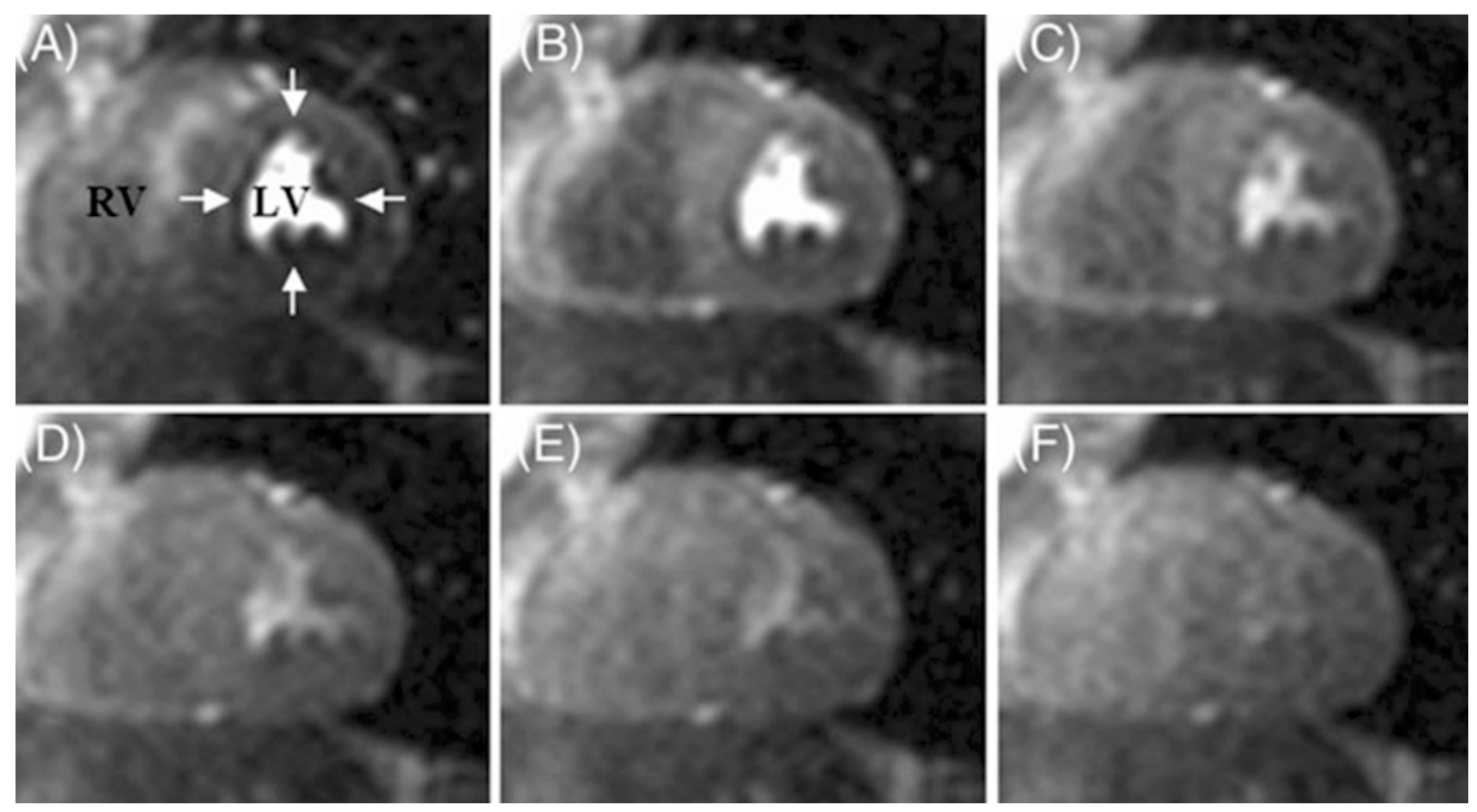

FIGURE 5: Short lasting Gadolinium enhanced first pass perfusion defects seen in short axis left ventricular cuts during first three to four beats (A-D) and subsequent disappearance 
ischaemia $(0.1 \mathrm{mV}$ horizontal or downsloping ST-segment depression of $80 \mathrm{~ms}$ after the $\mathrm{J}$ point), and/or a reversible perfusion defect on a myocardial SPECT; and completely normal results from coronary angiography. However, the selection of syndrome X patients using both exercise-ECG and SPECT is an accepted method used by almost 11 studies on cardiac syndrome X so far ${ }^{15}$.

In our study we found dark rim artifacts during the peak gadolinium concentration in the left ventricular blood-pool MRI images in most of the patients in both the study and control group. These artifacts were very short lasting. They were seen for initial 4-5 beats with rapid disappearance later. This temporary signal loss is considered to be an artifact related to the first-pass sequence and is not typical for an ischaemiarelated defect, which shows a more sustained signal loss. These dark rims along parts of the subendocardial border of the left ventricle and the myocardium has been noticed in dynamic contrast-enhanced MR perfusion studies. ${ }^{16,17}$ Several causes have been proposed for this so-called dark rim artifact, such as cardiac motion, Gibbs ringing due to limited spatial resolution and susceptibility. Considering the spatial resolution and the cardiac acquisition window applied in this study, it is not to be expected that we experienced more artifacts compared to the study of Panting etal. ${ }^{12}$ Similar short lasting artifacts were found in all patients in the study by Vermeltfoort et $a^{14}$.

Chest pain in response to adenosine ranging from mild to severe was found in almost all the patients in both the study and control groups in our study, although a higher grade of pain was found in study group. Severe pain in response to adenosine has been found in healthy volunteers in many studies and in $86 \%$ of patients with cardiac syndrome $\mathrm{X}$ in the study done by Vermeltfoort et al, in whom no evidence of subendocardial ischemia was found either by visual assessment or quantitative analysis on cardiac MRI. Adenosine is known to cause chest pain in healthy volunteers but this higher grade of pain in response to adenosine in patients with cardiac syndrome $\mathrm{x}$ in our study and the study by Vermeltfoort et al might mean an abnormal pain perception in these patients. This enhanced pain perception in response to adenosine has been found in other studies as well ${ }^{18}$.

In our study we did not find any evidence of microvascular dysfunction in either subendocardium or epicardium in patients with syndrome $\mathrm{X}$, as both the study and control groups showed a clear increase of almost similar magnitude in myocardial perfusion index in response to adenosine.

The pathogenesis of cardiac syndrome $\mathrm{X}$ is unclear. The main hypotheses for its occurrence are microvascular dysfunction or abnormal pain perception. There have been conflicting data concerning the possible role of myocardial ischaemia in syndrome X. Several studies of patients with syndrome $\mathrm{X}$ demonstrated ischaemia whereas other investigations found no confirmatory evidence of ischaemia during stress in these patients. Alternative non-ischaemic mechanisms of chest pain have been proposed in patients with cardiac syndrome X. Panza et al by virtue of radionuclide angio, thallium stress and dobutamine stress echo found evidence against ischemia in syndrome $\mathrm{X}^{19}$. Camici etal found normal myocardial metabolism and LV functions upon incremental pacing in cardiac syndrome $\mathrm{X}^{20}$. Shapiro et a $\mathbf{l}^{21}$ Chauhan $e t$ a ${ }^{22}$ found abnormal pain perception to catheter induced right atrial stimulation. Cannon RO $111^{23}$ found abnormal pain perception to catheter manipulation and pacing. Pasceri et $a l^{24}$ detected abnormal pain perception to electrical stimuli. Lanza et al ${ }^{25}$ found abnormal cardiac adrenergic function. Fedel et $a l^{26}$ and Rosen D et al ${ }^{27}$ found evidence in favour of abnormal central neural handling of painful stimuli.

The exact mechanism of chest pain in patients with syndrome X remains unclear since our data does not support the hypothesis of subendocardial ischaemia in this patient group. We consider the relatively small number of patients and the frequent occurrence of subendocardial artefacts with CMR as the major study limitations.

\section{Conclusion}

We conclude that our cardiovascular MRI study of patients with chest pain, positive exercise ECG stress testing, and normal coronary angiography, demonstrated significant and of almost similar magnitude adenosine-induced increases in both subendocardial and subepicardial MPIs in both study and control groups. We found no evidence for specific subendocardial ischaemia with MRI in the study group of patients.

\section{Future directions}

Taking into account various studies so far done on cardiac syndrome $\mathrm{X}$, there is a possibility that its pathogenesis may be heterogenous. we advocate that larger studies taking into account various different groups of patients and using different stress protocols for cardiac MRI in these patients may elucidate the cause of chest pain in cardiac syndromeX.

\section{References}

1. Proudfit WL, Shirey EK, Sones FM Jr. Selective cine coronary arteriography: correlation with clinical findings in 1,000 patients. Circulation 1966;33:901-910.

2. Kemp HG Jr. Left ventricular function in patients with the anginal syndrome and normal coronary arteriograms. Am J Cardiol 1973;32:375-376.

3. Yildiz M, Altun A, Ozbay G. Assessment of arterial distensibility in patients with cardiac syndromeX. Angiology 2007; 58:458-462.

4. Crea F, Lanza G A, Zipes DP, Libby P, Bonow RO, et al. Angina pectoris and normal coronary arteries. Heart 2004; 90:457-463.

5. Kao CH, Wang SJ, Ting CT, Chen YT. Thallium-201 myocardial SPECT in strictly defined syndrome X. Nucl 


\section{Med Commun 1995;16:640-646.}

6. Kao CH, Wang SJ, Ting CT, Chen 280-283YT. Tc-99m sestamibi myocardial SPECT insyndrome X. Clin Nud Med 1996;21.

7. Cannon RO III, Bonow RO, Bacharach SL, et al. Left ventricular dysfunction in patients with angina pectoris, normal epicardial coronary arteries, and abnormal vasodilator reserve. Circulation 1985;71:218-226.

8. Nihoyannopoulos P, Kaski J C, Crake T, et al. Absence of myocardial dysfunction during stress in patients with syndrome X.J Am Coll Cardiol 1991;18;1463-1470.

9. Legrand V, Hodgson JM, Bates ER, et al. Abnormal coronary flow reserve and abnormal radionuclide exercise test results in patients with normal coronary angiograms. JAm Coll Cardiol 1985;6:1245-1253.

10. Panza JA,Laurienzo JM,Curiel RV,Unger EF,Quyyumi AA, Dilsizian V, Cannon RO III. Investigation of the mechanism of chest pain in patients with angiographically normal coronary arteries using transesophageal dobutamine stress echocardiography. J Am Coll Cardiol 1997;29:293-301.

11. Buchthal SD, den Hollander JA, Merz CNB, et al. Abnormal myocardial phosphorus 31 nuclear magnetic resonance spectroscopy in women with chest pain but normal coronary angiograms. N Engl J Med 2000;342: 829-835.

12. Camici PG, Marraccini P, Lorenzoni R, et al. Coronary hemodynamics and myocardial metabolism in patients with syndrome $\mathrm{X}$ : response to pacing stress. J Am Coll Cardiol 1991;17:1461-1470.

13. Panting JR, Gatehouse PD, Yang GZ, et al. Abnormal subendocardial perfusion in cardiac syndrome $\mathrm{X}$ detected by cardiovascular magnetic resonance imaging. $N$ Engl J Med 2002;346;1948-1953.

14. Vermeltfoort I, Raijmakers P, Hofman M, van Rossum, B. Is subendocardial ischaemia present in patients with chest pain and normal coronary angiograms? A cardiovascular MR study: reply. Eur Heart J 2007;28:2688-2688.

15. C Vermeltfoort, PGHM Raijmakers, IIRiphagen, DAM Odekerken, AFM Kuijper, A Zwijnenburg, GJJTeule. Definitions and incidence of cardiac syndrome X: review and analysis of clinical data. Clin Res Cardiol 2010 August; 99(8):475-481.

16. Storey P, Chen Q, Li W, Edelman RR, Prasad PV. Band artifacts due to bulkmotion. Magn Reson Med 2002; 48 : 1028-1036.
17. Di Bella EV, Parker DL, Sinusas AJ. On the dark rim artifact in dynamiccontrast-enhanced MRI myocardial perfusion studies. Magn Reson Med 2005;54:1295-1299.

18. Lagerqvis B, Sylven C, Waldenstrom A. Lower threshold for adenosine-induced chest pain in patients with angina and normal coronary angiograms. Br Heart J 1992; 68: 282-285

19. Panza JA, Laurienzo JM,Curiel RV,Unger EF,Quyyumi AA, Dilsizian V, Cannon RO III. Investigation of the mechanism of chest pain in patients with angiographically normal coronary arteries using transesophageal dobutamine stress echocardiography. J Am Coll Cardiol 1997;29:293-301.

20. Camici PG, Gistri R, Lorenzoni R, et al. Coronary reserve and exercise ECG in patients with chest pain and normal coronary angiograms. Circulation 1992;86:179-186.

21. Shapiro L M, Crake T, Poole Wilson P A. Is altered cardiac sensation responsible for chest pain in patients with normal coronary arteries? Clinical observations during cardiac catheterization. BMJ 1988.29;6:170-171.

22. Chauhan A, Mullins PA, Taylor M, et al. Both endothelium-dependent and endothelium-independent function is impaired in patients with angina pectoris and normal coronary angiograms. Eur Heart J 1997;18:60-8.

23. Cannon RO, 3rd, Quyyumi AA, Schenke WH, et al. Abnormal cardiac sensitivity in patients with chest pain and normal coronary arteries. J Am Coll Cardiol 1990;16: 1359-1366.

24. Pasceri V, Lanza G A, Buffon A, et al Role of abnormal pain sensitivity and behavioral factors in determining chest pain in syndrome X. J Am Coll Cardiol 1998; 3162-66.

25. Lanza GA, Giordano A, Pristipino C, et al. Abnormal cardiac adrenergic nerve function in patients with syndrome X detected by [123I] metaiodobenzylguanidine myocardial cintigraphy. Circulation 1997;96: 821-826.

26. Fedele F, Agati L, Pugliese M, et al. Role of the central endogenous opiate system in patients with syndrome X. Am Heart J 1998;136:1003-1009.

27. Rosen S D, Paulesu E, Wise R J S, et al. Central neural contribution to the perception of chest pain in cardiac syndrome X. Heart 2002;87:513-519.

28. Maseri A, Crea F, Kaski JC, et al. Mechanisms of angina pectoris in syndrome X. J Am Coll Cardiol 1991;17: 499-506. 